\title{
Erratum to: A first inventory of the labile biochemicals found in Avignon groundwater: can we identify potential bacterial substrates?
}

Ludivine Rousset ${ }^{1,2, \mathrm{co}}$, Marina Gillon ${ }^{3, \mathrm{co}}$, Catherine Duport ${ }^{1}$, Thierry Clavel $^{1}$, Marie Lagrée ${ }^{4}$, Mounir Traikia ${ }^{4}$, Christos Panagiotopoulos ${ }^{5}$ and Odile Berge ${ }^{2 *}$

${ }^{1}$ UMR408, Sécurité et Qualité des Produits d’Origine Végétale (SQPOV), Avignon University, INRA-PACA, 84000 Avignon, France ${ }^{2}$ MISTRAL, INRA-PACA, Plant Pathology Research Unit, 84143 Avignon, France

${ }^{3}$ EMMAH, UMR 1114, Avignon University, 84000 Avignon, France

${ }^{4}$ Université Clermont Auvergne-CNRS-SIGMA-Clermont, Institut de Chimie de Clermont-Ferrand, France

${ }^{5}$ Aix Marseille Univ, Université de Toulon, CNRS, IRD, MIOss, Marseille, France

Original article: E3S Web of Conferences 88, 02001 (2019), https://doi.org/10.1051/e3sconf/20198802001

The address \# 5 should be replaced by the following text:

${ }^{5}$ Aix Marseille Univ, Université de Toulon, CNRS, IRD, MIO, Marseille, France 